\title{
A comparison of immunomagnetic separation and direct culture for the isolation of verocytotoxin-producing Escherichia coli 0157 from bovine faeces
}

\author{
P. A. CHAPMAN, D. J. WRIGHT and C. A. SIDDONS
}

Public Health Laboratory, Herries Road, Sheffield S5 7BO

\begin{abstract}
Summary. Enrichment culture (EC) in modified buffered peptone water followed by immunomagnetic separation (IMS) with magnetic beads coated with an antibody against Escherichia coli $\mathrm{O} 157$ (Dynabeads anti-E. coli O157; Dynal, Oslo) was compared with direct culture on cefixime rhamnose sorbitol MacConkey agar (CR-SMAC) and cefixime tellurite sorbitol MacConkey agar (CT-SMAC) for the isolation of E. coli O157 from bovine faeces. When used to examine bovine faecal suspensions inoculated with 12 different strains of $E$. coli O157, EC-IMS was $c$. 100-fold more sensitive for detection of the organism than direct culture on either medium. During monitoring of a dairy herd, E. coli $\mathrm{O} 157$ was isolated from $84(8.2 \%)$ of 1024 rectal swabs taken from cattle over a 4-month period; $23(27.4 \%$ of the 84 strains were isolated by both direct culture and IMS ( 15 of the 23 were isolated on both media, five on CT-SMAC only and three on CR-SMAC only), whereas $61(72.6 \%)$ strains were isolated by IMS only. IMS is a sensitive and simple technique for the isolation of E. coli O157 from bovine faecal samples and should prove useful in elucidating further the epidemiology of this organism.
\end{abstract}

\section{Introduction}

Verocytotoxin-producing Escherichia coli (VTEC) are now recognised as a major cause of haemorrhagic colitis (HC) and the haemolytic-uraemic syndrome (HUS), both conditions with high morbidity and mortality. In the UK, strains of verocytotoxinproducing $\left(\mathrm{VT}^{+}\right)$E. coli $\mathrm{O} 157$, the most common serogroup associated with illness in man, have been isolated from cattle ${ }^{1-3}$ but the epidemiology of the organism remains unclear. In view of the potential severity of infections caused by $\mathrm{VT}^{+}$E. coli $\mathrm{O} 157$, it is essential that the most sensitive methods available are used in studies designed to elucidate further the reservoirs of the organism and routes of transmission of the organism to man.

$\mathrm{VT}^{+}$E. coli $\mathrm{O} 157$ strains do not ferment sorbitol whereas most other serogroups of $E$. coli do and sorbitol MacConkey agar has proved useful for their isolation. ${ }^{4}$ Improvements to sorbitol MacConkey medium $^{5,6}$ have resulted in increased sensitivity of isolation of $E$. coli $\mathrm{O} 157$ from faecal samples but efficient selective enrichment media for E. coli $\mathrm{O} 157$ have not been described.

The aim of this study was to evaluate the use of enrichment culture (EC) in modified buffered peptone water ${ }^{2}$ followed by immunomagnetic separation (IMS) for the isolation of $E$. coli from bovine faeces.

Received 2 Dec. 1993; accepted 16 Dec. 1993.
Artificially inoculated faecal samples, and samples collected both during the investigation of a possible outbreak of milk-borne infection by $\mathrm{VT}^{+}$E. coli $\mathrm{O} 157$ in the Sheffield area $^{3}$ in May 1993 and during the subsequent monitoring of the dairy herd jointly by MAFF and PHLS, were used to compare direct culture with the IMS technique for isolation of E. coli O157.

\section{Materials and methods}

Preparation of inoculated faecal samples

Twelve different strains of E. coli $\mathrm{O} 157$ previously isolated from bovine faeces ${ }^{2}$ were each grown overnight at $37^{\circ} \mathrm{C}$ in nutrient broth and the viable counts $(\mathrm{cfu} / \mathrm{ml})$ were estimated by a standard serial dilution method. The strains used were: P1394 O157: $\mathrm{H}^{-}$ $\mathrm{VT}_{1}{ }^{-} \mathrm{VT}_{2}{ }^{+}$phage type (PT) 2; P1396 O157:H7 $\mathrm{VT}_{1}{ }^{-} \mathrm{VT}_{2}{ }^{+} \mathrm{PT} 2$; P1431 O157: $\mathrm{H}^{-} \mathrm{VT}_{1}{ }^{-} \mathrm{VT}_{2}{ }^{+} \mathrm{PT} 4$; P1446 O157:H7 $\mathrm{VT}_{1}{ }^{+} \mathrm{VT}_{2}{ }^{+} \mathrm{PT} 4$; P1426 O157: $\mathrm{H}^{-}$ $\mathrm{VT}_{1}{ }^{+} \mathrm{VT}_{2}{ }^{+} \mathrm{PT} 8$; P1506 O157:H7 $\mathrm{VT}_{1}^{-} \mathrm{VT}_{2}{ }^{+} \mathrm{PT} 8$; P1401 O157:H7 $\mathrm{VT}_{1}{ }^{+} \mathrm{VT}_{2}{ }^{+}$PT14; P1523 O157:H7 $\mathrm{VT}_{1}^{-} \mathrm{VT}_{2}{ }^{+} \mathrm{PT} 14$; P1524 O157:H7 $\mathrm{VT}_{1}{ }^{+} \mathrm{VT}_{2}{ }^{-} \mathrm{PT} 14$; P1430 O157: $\mathrm{H}^{-} \mathrm{VT}_{1}{ }^{-} \mathrm{VT}_{2}{ }^{+}$PT49; P1519 O157:H7 $\mathrm{VT}_{1}{ }^{-} \mathrm{VT}_{2}{ }^{+} \mathrm{PT} 49$; and P1400 O157: $\mathrm{H}^{-} \mathrm{VT}_{1}{ }^{-} \mathrm{VT}_{2}{ }^{-} \mathrm{PT}$ RDNC.

Ten samples of bovine faeces containing large numbers of sorbitol-fermenting (SF) E. coli, but from which $E$. coli $\mathrm{O} 157$ could not be isolated, were used to make a suspension of faeces $c .50 \% \mathrm{v} / \mathrm{v}$ in buffered 
peptone water, which was then used to prepare suspensions containing each of the above $E$. coli $\mathrm{O} 157$ strains at concentrations of $c .10^{6}, 10^{5}, 10^{4}, 10^{3}, 100$ and $10 \mathrm{cfu} / \mathrm{ml}$.

\section{Collection of faecal samples from dairy cattle}

Samples of faeces were collected by rectal swabs from dairy cattle; 1024 swabs were collected from 118 milking cows, 25 in-calf heifers, 16 calves and 8 dry cows. Samples were collected at approximately 2 -week intervals over a 4-month period from late May until late August by colleagues from the MAFF Veterinary Investigations Centre, Thirsk, and were transported immediately to Sheffield Public Health Laboratory for microbiological examination.

\section{Direct culture of E. coli 0157}

Samples (either rectal swabs or $20 \mu$ of inoculated faecal suspension) were inoculated on to cefixime rhamnose sorbitol MacConkey (CR-SMAC) medium ${ }^{5}$ and cefixime tellurite sorbitol MacConkey (CTSMAC) medium. ${ }^{6}$ After incubation overnight at $37^{\circ} \mathrm{C}$, apparently sorbitol and rhamnose non-fermenting colonies from CR-SMAC and apparently sorbitol non-fermenting colonies from CT-SMAC were tested for agglutination with a latex test kit (Oxoid; DR622) for detecting $E$. coli $\mathrm{O} 157 .^{7}$ Isolates that gave positive results with this test were further characterised as described below.

\section{Immunomagnetic separation of E. coli 0157}

After direct culture, swabs (or $100 \mu$ l of inoculated faecal suspension) were placed in $5 \mathrm{ml}$ of buffered peptone water (Oxoid; CM509) supplemented with vancomycin $8 \mathrm{mg} / \mathrm{L}$, cefixime $0.05 \mathrm{mg} / \mathrm{L}$ and cefsulodin $10 \mathrm{mg} / \mathrm{L}$ to inhibit the growth of gram-positive organisms, aeromonads and Proteus spp., respectively. ${ }^{2}$ After vortex mixing, broths were incubated at $37^{\circ} \mathrm{C}$ for $6 \mathrm{~h}$ and $1 \mathrm{ml}$ of broth was added to $20 \mu \mathrm{l}$ of magnetic beads coated with an antibody against $E$. coli O157 (Dynabeads anti-E. coli O157; Dynal, Oslo) in a $1 \cdot 5-\mathrm{ml}$ microcentrifuge tube. The beads were suspended evenly in the broth culture by vortex mixing and were placed in a rotating mixer so that they were mixed by inversion every $2-3 \mathrm{~s}$ for $30 \mathrm{~min}$ at ambient temperature. Tubes were placed in a magnetic separator rack (MPC-10; Dynal, Oslo) and the magnets were placed in position and left for $5 \mathrm{~min}$. The culture supernate was removed by aspiration with a pasteur pipette, the magnetic slide was removed from the rack, the beads were washed by resuspension in $1 \mathrm{ml}$ of PBS, $\mathrm{pH} 7 \cdot 2$, with Tween $200.002 \% \mathrm{v} / \mathrm{v}$ (PBST) and the magnetic slide was replaced for $2 \mathrm{~min}$. The beads were washed in PBST in this way a further two times, the magnetic slide was replaced for $2 \mathrm{~min}$, the supernate was removed and the beads were resuspended in $c$. $25 \mu$ l of PBS. Beads were inoculated on to CT-SMAC medium and incubated overnight at $37^{\circ} \mathrm{C}$. Sorbitol non-fermenting colonies were examined as above.

\section{Characterisation of isolates}

Identification. As described previously, ${ }^{7}$ isolates that gave a positive latex test result were confirmed as $E$. coli by biochemical tests and confirmed as serogroup O157 by agglutination to titre with antiserum to $E$. coli O157 (Laboratory for Microbiological Reagents, Central Public Health Laboratory, 61 Colindale Avenue, London).

Verocytotoxin production. Toxigenicity was determined by Vero cell culture assay. ${ }^{1}$ Toxin type was determined by specific hybridisation with DNA probes for the $\mathrm{VT}_{1}$ and $\mathrm{VT}_{2}$ genes. DNA specific for the $\mathrm{A}$ cistrons of the $\mathrm{VT}_{1}$ and $\mathrm{VT}_{2}$ genes was prepared by the polymerase chain reaction, random-prime labelled with digoxigenin-11-dUTP, and used in colony hybridisation reactions as described previously. ${ }^{2,8}$ Known $\mathrm{VT}_{1}^{+}, \mathrm{VT}_{2}{ }^{+}$and $\mathrm{VT}^{-}$strains were included as controls in each batch of tests.

Plasmid analysis. Plasmids were extracted by an alkaline detergent method $^{9}$ and were separated by submerged gel electrophoresis in Tris-acetate-EDTA buffer with agarose $1 \%$, stained by ethidium bromide and visualised on an ultraviolet transilluminator. A control $E$. coli K-12 strain (NCTC 50192-39R861) harbouring plasmids of $148,63.4,36$ and $6.9 \mathrm{~kb}$ was included with each batch of tests. For this control strain, $\log _{10}$ of plasmid size was plotted against distance migrated through the agarose gel and approximate sizes of plasmids from strains of $E$. coli O157 were estimated from this graph.

Phage typing. All E. coli $\mathrm{O} 157$ strains were phage typed by the Laboratory for Enteric Pathogens, Central Public Health Laboratory.

\section{Results}

\section{Preliminary evaluation of IMS}

The detection limits and approximate ratios of SF $E$. coli: $E$. coli $\mathrm{O} 157$ for both direct culture and ECIMS are shown in detail in table I. EC-IMS was $c$. 100fold more sensitive than direct culture on either CRSMAC or CT-SMAC for the recovery of most of the strains of $E$. coli $\mathrm{O} 157$.

\section{Isolation of E. coli 0157 from cattle in a dairy herd}

E. coli $\mathrm{O} 157$ was isolated from $84(8 \cdot 2 \%)$ of 1024 bovine rectal swabs : $23(27 \cdot 4 \%)$ of the 84 strains were isolated by both direct culture and EC-IMS (15 of the 23 were isolated on both media, five on CT-SMAC only and three on CR-SMAC only), whereas 61 $(72.6 \%)$ strains were isolated by EC-IMS only (table II).

All strains were confirmed as VT producers by a cell culture assay, hybridised with the DNA probe for $\mathrm{VT}_{2}$ 
Table I. Evaluation of IMS with 12 different strains of E. coli 0157

\begin{tabular}{|c|c|c|c|c|c|c|}
\hline \multirow{2}{*}{ Strain no. } & \multicolumn{2}{|c|}{ CR-SMAC } & \multicolumn{2}{|c|}{ CT-SMAC } & \multicolumn{2}{|c|}{ IMS } \\
\hline & Limit & Ratio & Limit & Ratio & Limit & Ratio \\
\hline P1394 & $10^{5}$ & $+++1+$ & $10^{5}$ & $+++1++$ & 100 & $++/++$ \\
\hline P1396 & $10^{5}$ & $+++1+$ & $10^{5}$ & $++/++$ & $10^{3}$ & $-1+++$ \\
\hline P1431 & $10^{4}$ & $+++1+$ & $10^{5}$ & $++1+++$ & 100 & $+1+++$ \\
\hline P1446 & $10^{5}$ & $+++1+$ & $10^{5}$ & $+t+1+$ & 100 & $++1++$ \\
\hline P1426 & $10^{4}$ & $+++1+$ & $10^{4}$ & $+++1++$ & 100 & $+1+++$ \\
\hline P1506 & $10^{5}$ & $+++1+$ & $10^{5}$ & $+++/+$ & $10^{3}$ & $-1+++$ \\
\hline P1401 & $10^{5}$ & $+++/+$ & $10^{5}$ & $+++1++$ & $10^{3}$ & $-1+t+$ \\
\hline $\mathrm{P} 1523$ & $10^{5}$ & $+++1+$ & $10^{5}$ & $+++1++$ & $10^{3}$ & $-1+++$ \\
\hline P1524 & $10^{5}$ & $+++1+$ & $10^{5}$ & $+++/ t$ & $10^{3}$ & $-1+++$ \\
\hline $\mathrm{P} 1430$ & $10^{5}$ & $+++1+$ & $10^{4}$ & $+++/++$ & 100 & $+1+t+$ \\
\hline P1519 & $10^{5}$ & $+++1+$ & $10^{5}$ & $++t+$ & $10^{3}$ & $-1+++$ \\
\hline P1400 & $10^{5}$ & $+++1+$ & $10^{4}$ & $+++1+$ & $10^{3}$ & $-1+++$ \\
\hline
\end{tabular}

Limit, lowest detectable number of $E$. coli $\mathrm{O} 157 / \mathrm{ml}$ of faecal suspension; ratio, approximate ratio of colonies of sorbitol-fermenting $E$. coli $/ E$. coli $\mathrm{O} 157 ;-$, not detected;,$+<10$ colonies;,$++ 10-100$ colonies;,$+++>100$ colonies.

Table II. Isolation of E. coli $\mathrm{O} 157$ from 1024 bovine rectal swabs

\begin{tabular}{ccc|c}
\hline \multicolumn{3}{c|}{ Isolation achieved by } & \multirow{2}{*}{ Number of isolates } \\
\cline { 1 - 2 } CR-SMAC & CT-SMAC & EC-IMS & \\
\hline+ & + & + & 15 \\
- & + & + & 5 \\
+ & - & + & 3 \\
- & - & + & 61 \\
Total & & & \\
\hline
\end{tabular}

CR-SMAC, direct culture on cefixime rhamnose sorbitol MacConkey agar; CT-SMAC, direct culture on cefixime tellurite sorbitol MacConkey agar; EC-IMS, pre-enrichment culture in modified buffered peptone water, immunomagnetic separation of $E$. coli O157 and subculture on CT-SMAC; +, E. coli O157 isolated; - , E. coli $\mathrm{O} 157$ not isolated.

but not with that for $\mathrm{VT}_{1}$, harboured a single $92-\mathrm{kb}$ plasmid and were of phage type 2 .

\section{Discussion}

Cattle appear to be a major reservoir of $\mathrm{VT}^{+} E$. coli 0157 and the organism has been isolated from apparently healthy animals while investigating sources of human infection in Canada, ${ }^{10}$ the USA ${ }^{11-13}$ and England. ${ }^{1-3}$ Therefore, sensitive methods for detecting $\mathrm{VT}^{+} E$. coli $\mathrm{O} 157$ in bovine faeces are necessary for epidemiological studies. $\mathrm{VT}^{+} E$. coli $\mathrm{O} 157$ strains do not ferment sorbitol, whereas most other $E$. coli strains do, and sorbitol MacConkey (SMAC) medium has become widely used for their isolation. However, SMAC medium relies entirely on differential sugar fermentation and does not select $\mathrm{VT}^{+} E$. coli $\mathrm{O} 157$ from other $E$. coli or sorbitol non-fermenting genera and, therefore, lacks sensitivity. SMAC media incorporating cefixime and rhamnose (CR-SMAC) ${ }^{5}$ or cefixime and tellurite (CT-SMAC) ${ }^{6}$ have been shown previously to be more efficient than unmodified SMAC medium for the isolation of the organism from human faeces and bovine faeces, respectively. In this study, the sensitivities of CT-SMAC and CR-SMAC were not apparently different for the isolation of 12 different strains of $E$. coli $\mathrm{O} 157$ from artificially inoculated bovine faecal suspensions, but the greater ratio of $E$. coli O157: SF E. coli usually observed on CT-SMAC meant that the organism was easier to obtain in pure culture from the CT-SMAC medium.

A 6-h period of enrichment culture in buffered peptone water supplemented with vancomycin, cefixime and cefsulodin followed by subculture to CRSMAC was more sensitive than direct culture on CRSMAC for detecting $E$. coli $\mathrm{O} 157$ on beef carcasses, ${ }^{2}$ but was less sensitive than direct culture on CRSMAC for detecting the organism in faecal samples due to heavy overgrowth of other organisms (Sheffield PHL, unpublished data).

IMS has been shown to be more sensitive than direct culture for the isolation of $E$. coli $\mathrm{O} 157$ from artificially mixed cultures and inoculated meat samples. ${ }^{14,15}$ The present study has confirmed that EC followed by IMS is $c$. 100 -fold more sensitive than direct culture on either CR-SMAC or CT-SMAC for detecting a range of types of $E$. coli $\mathrm{O} 157$ in inoculated bovine faeces. On examination of 1024 bovine rectal swabs, E. coli $\mathrm{O} 157$ was isolated from 23 by direct culture; 15 of the 23 were isolated on both CR-SMAC and CT-SMAC, five on CT-SMAC only and three on CR-SMAC only. $E$. coli $\mathrm{O} 157$ was isolated from 84 swabs by EC-IMS and these included the 23 that were isolated by direct culture; this provides further evidence of the enhanced sensitivity of the EC-IMS technique. All strains were confirmed as typical $\mathrm{VT}^{+}$E. coli $\mathrm{O} 157$ by phage typing, plasmid content and DNA hybridisation for toxin genes.

Other immunological methods have been described for the detection of $E$. coli O157, including enzyme immunoassay ${ }^{16,17}$ and immunoblot techniques. ${ }^{18,19}$ Although sensitive, these methods may be timeconsuming, technically demanding, expensive and prone to give positive results that cannot be confirmed 
by culture. In contrast, EC-IMS is rapid, technically simple and, most importantly, yields an isolate of $E$. coli that may be useful in epidemiological studies.

Monitoring of the dairy herd is continuing to help understand further the epidemiology of this organism.

\section{References}

1. Chapman PA, Wright DJ, Norman P. Verotoxin-producing Escherichia coli infections in Sheffield: cattle as a possible source. Epidemiol Infect 1989; 102: 439-445.

2. Chapman PA, Siddons CA, Wright DJ, Norman P, Fox J, Crick E. Cattle as a possible source of verocytotoxin-producing Escherichia coli $\mathrm{O} 157$ infections in man. Epidemiol Infect 1993; 111: 439-447.

3. Chapman PA, Wright DJ, Higgins R. Untreated milk as a source of verotoxigenic $E$. coli O157. Vet Rec 1993; 133: 171-172.

4. March SB, Ratnam S. Sorbitol-MacConkey medium for the detection of Escherichia coli O157: $\mathrm{H} 7$ associated with hemorrhagic colitis. J Clin Microbiol 1986; 23: 869-872.

5. Chapman PA, Siddons CA, Zadik PM, Jewes L. An improved selective medium for the isolation of Escherichia coli O157. J Med Microbiol 1991; 35: 107-110.

6. Zadik PM, Chapman PA, Siddons CA. Use of tellurite for the selection of verocytotoxigenic Escherichia coli O157.J Med Microbiol 1993; 39: 155-158.

7. Chapman PA. Evaluation of commercial latex slide test for identifying Escherichia coli O157. J Clin Pathol 1989; 42: $1109-1110$.

8. Chapman PA, Daly CM. Evaluation of a non-radioactive trivalent DNA probe (LTh, STla, ST1b) for detecting enterotoxigenic Escherichia coli. J Clin Pathol 1993; 46: 309-312.

9. Chapman PA, Jewes L, Siddons CA, Norman P, George SL. Verotoxin-producing Escherichia coli infections in Sheffield during 1989. PHLS Microbiol Digest 1990; 7: 163-166.

10. Borczyk AA, Karmali MA, Lior H, Duncan LMC. Bovine reservoir for verotoxin-producing Escherichia coli O157:H7. Lancet 1987; 1 : 98.
We thank Dynal (UK) Ltd and Dynal AS (Oslo) for their cooperation in the development of the IMS technique and for providing coated beads for this study; $\mathrm{Dr}$ B. Rowe, Laboratory for Enteric Pathogens, Central Public Health Laboratory, 61 Colindale Avenue, London for phage typing the $E$. coli $\mathrm{O} 157$ strains and our colleagues at the MAFF Veterinary Investigations Centre, Thirsk, for their collaboration with the herd study.

11. Martin ML, Shipman LD, Wells JG et al. Isolation of Escherichia coli $\mathrm{O} 157: \mathrm{H} 7$ from dairy cattle associated with two cases of haemolytic uraemic syndrome. Lancet 1986; 2: 1043 .

12. Ostroff SM, Griffin PM, Tauxe RV et al. A statewide outbreak of Escherichia coli $\mathrm{O} 157$ infections in Washington state. Am J Epidemiol 1990; 132: 239-247.

13. Wells JG, Shipman LD, Greene KD et al. Isolation of Escherichia coli serotype 0157: $\mathrm{H} 7$ and other shiga-like toxin-producing $E$. coli from dairy cattle. J Clin Microbiol 1991; 29: 985-989.

14. Fratamico PM, Schultz FJ, Buchanan RL. Rapid isolation of Escherichia coli $\mathrm{O} 157: \mathrm{H} 7$ from enrichment cultures of foods using an immunomagnetic separation method. Food Microbiol 1992; 9: 105-113.

15. Okrend AJG, Bonnie ER, Lattuada CP. Isolation of Escherichia coli $\mathrm{O} 157: \mathrm{H} 7$ using $\mathrm{O} 157$ specific antibody coated magnetic beads. $J$ Food Protect 1992; 55: 214-217.

16. Padhye NV, Doyle MP. Production and characterization of a monoclonal antibody specific for enterohemorrhagic Escherichia coli of serotypes O157:H7 and O26:H11. J Clin Microbiol 1991; 29: 99-103.

17. Sernowski LP, Ingham SC. Frequency of false presumptive positive results obtained using a commercial ELISA kit to screen retail ground beef for Escherichia coli $0157: \mathrm{H} 7$. $J$ Food Protect 1992; 55 : 846.

18. Szabo RAE, Todd E, MacKenzie J, Parrington L, Armstrong A. Increased sensitivity of the rapid hydrophobic grid membrane filter enzyme labelled antibody procedure for Escherichia coli $\mathrm{O} 157$ detection in foods and bovine faeces. Appl Environ Microbiol 1990; 56: 3546-3549.

19. Doyle MP, Schoeni JL. Isolation of Escherichia coli O157:H7 from retail fresh meats and poultry. Appl Environ Microbiol 1987; 83: 2394-2396. 